\title{
Front Matter: Volume 6834
}

, "Front Matter: Volume 6834," Proc. SPIE 6834, Optical Design and Testing III, 683401 (26 February 2008); doi: 10.1117/12.784992

SPIE. Event: Photonics Asia 2007, 2007, Beijing, China 


\title{
PROCEEDINGS OF SPIE
}

\section{Optical Design and Testing III}

\author{
Yongtian Wang \\ Theo T. Tschudi \\ Jannick P. Rolland \\ Kimio Tatsuno \\ Editors
}

12-15 November 2007

Beijing, China

Sponsored by

SPIE - COS—Chinese Optical Society

\section{Cooperating Organizations}

OSJ-Optical Society of Japan - OSK-Optical Society of Korea - Australian Optical Society • Optical

Society of Singapore $\cdot$ Beijing Institute of Technology (China) $\bullet$ Beijing University of Posts and

Telecommunications (China) • Peking University (China) • Tsinghua University (China) • Zhejiang

University (China) • Changchun University of Science and Technology (China) • University of Shanghai

for Science and Technology (China) • Shanghai Jiao Tong University (China) • Tianjin University (China)

Nankai University (China) - Shanghai Institute of Optics and Fine Mechanics (China) • Changchun

Institute of Optics and Fine Mechanics (China) • Institute of Semiconductors (China) • Institute of Optics

and Electronics (China) - Shanghai Institute of Technical Physics (China) • China Instrument and Control Society • China Solid State Lighting Research and Industry Alliance • Optoelectronics Technology

Committee, COS (China)

Supporting Organizations

CAST_China Association for Science and Technology (China) - NNSF—National Nature Science

Foundation (China) • The Ministry of Science and Technology (China)

Published by

SPIE

Part One of Two Parts

Volume 6834

Proceedings of SPIE, 0277-786X, v. 6834 
The papers included in this volume were part of the technical conference cited on the cover and title page. Papers were selected and subject to review by the editors and conference program committee. Some conference presentations may not be available for publication. The papers published in these proceedings reflect the work and thoughts of the authors and are published herein as submitted. The publisher is not responsible for the validity of the information or for any outcomes resulting from reliance thereon.

Please use the following format to cite material from this book:

Author(s), "Title of Paper," in Optical Design and Testing III, edited by Yongtian Wang, Theo T. Tschudi, Jannick P. Rolland, Kimio Tatsuno, Proceedings of SPIE Vol. 6834 (SPIE, Bellingham, WA, 2007) Article CID Number.

ISSN 0277-786X

ISBN 9780819470096

Published by

SPIE

P.O. Box 10, Bellingham, Washington $98227-0010$ USA

Telephone +1 3606763290 (Pacific Time) · Fax +1 3606471445

SPIE.org

Copyright (c) 2008, Society of Photo-Optical Instrumentation Engineers

Copying of material in this book for internal or personal use, or for the internal or personal use of specific clients, beyond the fair use provisions granted by the U.S. Copyright Law is authorized by SPIE subject to payment of copying fees. The Transactional Reporting Service base fee for this volume is $\$ 18.00$ per article (or portion thereof), which should be paid directly to the Copyright Clearance Center (CCC), 222 Rosewood Drive, Danvers, MA 01923. Payment may also be made electronically through CCC Online at copyright.com. Other copying for republication, resale, advertising or promotion, or any form of systematic or multiple reproduction of any material in this book is prohibited except with permission in writing from the publisher. The CCC fee code is 0277-786X/08/\$18.00.

Printed in the United States of America.

Publication of record for individual papers is online in the SPIE Digital Library.

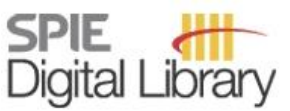

SPIEDigitalLibrary.org

Paper Numbering: Proceedings of SPIE follow an e-First publication model, with papers published first online and then in print and on CD-ROM. Papers are published as they are submitted and meet publication criteria. A unique, consistent, permanent citation identifier (CID) number is assigned to each article at the time of the first publication. Utilization of CIDs allows articles to be fully citable as soon they are published online, and connects the same identifier to all online, print, and electronic versions of the publication. SPIE uses a six-digit CID article numbering system in which:

- The first four digits correspond to the SPIE volume number.

- The last two digits indicate publication order within the volume using a Base 36 numbering system employing both numerals and letters. These two-number sets start with $00,01,02,03,04,05$, $06,07,08,09,0 \mathrm{~A}, 0 \mathrm{~B} \ldots \mathrm{OZ}$, followed by 10-1Z, 20-2Z, etc.

The CID number appears on each page of the manuscript. The complete citation is used on the first page, and an abbreviated version on subsequent pages. Numbers in the index correspond to the last two digits of the six-digit CID number. 


\title{
Contents
}

\section{Part One}

\author{
xv Conference Committee \\ xvii Symposium Committees \\ xix Introduction
}

\section{PLENARY PRESENTATION}

683402 The National Ignition Facility: the world's largest optical system (Plenary Paper) [6834-188] C. J. Stolz, Lawrence Livermore National Lab. (USA)

\section{SESSION 1 NANO-AND MICRO-OPTICS}

683403 Nano-glass imprinting technology for next-generation optical devices (Invited Paper) [6834-18]

J. Nishii, National Institute of Advanced Industrial Science and Technology (Japan)

683404 Technological strategy for advanced micro- and nano-structured optical elements (Invited Paper) [6834-159]

H. Kikuta, Osaka Prefecture Univ. (Japan)

683405 Bending insensitive optical curl cord patch cords based on Holey-fibers for FTTH (Invited Paper) [6834-01]

C.-H. Jung, C.-H. Ouh, K.-S. Ryu, H.-J. Kang, Optomagic Co., Ltd. (South Korea); S.-B. Lee, Korea Institute of Science and Technology (South Korea); Y.-G. Han, Hanyang Univ. (South Korea)

683406 Theoretical analysis of square GRIN lens [6834-05]

Z. Zhou, K. Chen, R. Zhang, Southwest Univ. of Science and Technology (China)

\section{SESSION 2 ILLUMINATION SYSTEM DESIGN}

683407 Backlight pattern optimization (Invited Paper) [6834-191]

W. J. Cassarly, Optical Research Associates (USA)

683408 Polarimetry of illumination for 193-nm lithography used for the manufacture of high-end LSIs (Invited Paper) [6834-08]

H. Nomura, Y. Furutono, Toshiba Corp. (Japan)

683409 A novel highly integrated light guide plate using micro optical technique [6834-73]

P. Xu, X. Chen, J. Huang, X. Zhang, L. Wan, K. Wang, J. Liu, Shenzhen Univ. (China) 
6834 OA Rays propagation in optical tunnel [6834-102]

Z. Liao, Institute of Optics and Electronics (China) and Graduate School of Chinese

Academy of Sciences (China); T. Xing, Institute of Optics and Electronics (China)

\section{SESSION 3 ASTRONOMICAL AND SPACE OPTICS}

$6834 \mathrm{OB} \quad$ Alignment induced aberration fields of next generation telescopes (Invited Paper) [6834-187]

K. Thompson, Optical Research Associates (USA); T. Schmid, J. Rolland, CREOL, Univ. of Central Florida (USA)

6834 OC The research on electric method for testing co-phasing error (Invited Paper) [6834-121] W. Zhao, G. Cao, Beijing Institute of Technology (China)

6834 OD Imaging analysis of optical sparse aperture systems with multiple-array configuration designs [6834-52]

J. Zhao, D. Wang, J. Han, Z. Jiang, Y. Wan, Beijing Univ. of Technology (China); H. Guo, National Astronomical Observatories (China); S. Tao, Beijing Univ. of Technology (China)

\section{SESSION 4 HEAD-MOUNTED DISPLAY DESIGN}

6834 OG Beyond the desktop: emerging technologies for supporting collaborative teams in virtual environments (Invited Paper) [6834-193]

J. Rolland, College of Optics and Photonics, Univ. of Central Florida (USA) and Univ. of Central Florida (USA); O. Cakmakci, K.-S. Lee, College of Optics and Photonics, Univ. of Central Florida (USA); C. Fidopiastis, College of Optics and Photonics, Univ. of Central Florida (USA) and Univ. of Central Florida (USA); F. Hamza-Lup, Armstrong Atlantic State Univ. (USA); A. Santhanam, College of Optics and Photonics, Univ. of Central Florida (USA), Univ. of Central Florida (USA), Armstrong Atlantic State Univ. (USA), and MD Anderson Cancer Ctr. Orlando (USA)

$6834 \mathrm{OH}$ Design of hybrid refractive-diffractive objective lens of head-mounted projective displays [6834-109]

Y. Zhang, Changchun Univ. of Science and Technology (China)

$6834 \mathrm{Ol}$ Research-oriented teaching in optical design course and its function in education [6834-155]

Z. Cen, X. Li, X. Liu, S. Deng, Zhejiang Univ. (China)

\section{SESSION 5 COMPACT OPTICS}

6834 OK Optical design, fabrication, and evaluation of optical systems using free-shaped prism (Invited Paper) [6834-131]

H. Ohde, T. Nagata, Olympus Corp. (Japan)

6834 OM Design of an objective lens for optical disc systems employing a blue laser by scalar diffraction simulation [6834-172]

N. Yamagata, S. Takeuchi, K. Yamanaka, D. Koreeda, K. Maruyama, Pentax Corp. (Japan) 
6834 ON Study on mathematical modeling for optical pickup virtual analyzer [6834-153]

X. Cheng, J. Ma, S. Yan, Tsinghua Univ. (China)

\section{SESSION $6 \quad$ INTERFEROMETRY IN OPTICAL TESTING}

$683400 \quad$ New low-cost metrology system for mass production (Invited Paper) [6834-23]

T. Blümel, M. Bosse, FISBA OPTIK GmbH (Germany); J. Fehse, Y. Gilliand, FISBA OPTIK AG

(Switzerland); R. Kafka, R. Neubert, FISBA OPTIK GmbH (Germany); C. Zellweger, FISBA OPTIK AG (Switzerland)

6834 OP A compact, high-speed, desktop turnkey measurement system for the characterization of the surface topography of spherical, aspherical, and toroidal surfaces [6834-150]

S. D. Fantone, D. A. Imrie, J. Zhang, Optikos Corp. (USA)

$6834 \mathrm{OQ}$ Mach-Zehnder optical interferometric polarimeter using two reference beams with different heterodyne frequency [6834-34]

H. Liu, Y. Li, G. Cui, Y. Zhang, J. Chen, J. Xu, Q. Sun, Nankai Univ. (China)

$6834 \mathrm{OR} \quad$ New interferometric algorithm for the measurement of phasing errors in spherical segmented-mirrors system [6834-25]

F. Yu, M. Hui, Y. Zhao, F. Liu, Beijing Institute of Technology (China)

6834 OS Inhomogeneous radial shearing technique [6834-164]

Z. Ghadyani, Univ. of Tehran (Iran)

\section{SESSION 7 TESTING FOR ASPHERIC SURFACES}

6834 OT Study on testing larger asphericity in non-null interferometer (Invited Paper) [6834-180]

Y. Yang, D. Liu, Y. Shen, J. Weng, Y. Zhuo, Zhejiang Univ. (China)

6834 OU System optimization of radial shearing interferometer for aspheric testing [6834-178]

D. Liu, Y. Yang, Y. Shen, J. Weng, Y. Zhuo, Zhejiang Univ. (China)

\section{SESSION 8 NOVEL SYSTEM DESIGN}

6834 OW Optics for digital photography (Invited Paper) [6834-196]

K. Lenhardt, Jos. Schneider Optische Werke GmbH (Germany)

6834 OY Compact hyperspectral imaging system with a convex grating [6834-51]

Y. Ji, W. Shen, Soochow Univ. (China)

6834 OZ Design of a lens system within mobile terminal [6834-158]

J. Liu, Huazhong Univ. of Science and Technology (China) and China Aerodynamics Research and Development Ctr. (China); J. Ding, Beijing Institute of Technology (China)

683410 Singlet mega-pixel resolution lens [6834-136]

C.-H. Lin, H. Y. Lin, National Taiwan Univ. (Taiwan, China); H. Chang, Fu Jen Catholic Univ. (Taiwan, China) 
683411 High-resolution imaging of phase-distorted extended object using SPGD algorithm and deformable mirror [6834-19]

H. Yang, Institute of Optics and Electronics (China) and Graduate Univ. of Chinese Academy of Sciences (China); X. Li, W. Jiang, Institute of Optics and Electronics (China)

683412 Wavefront sensing [6834-177]

M. Garcia, F. Granados, A. Cornejo, National Institute of Astrophysics, Optics and Electronics (Mexico)

683413 Wavefront error correction with stochastic parallel gradient descent algorithm [6834-41] J. Liu, L. Li, X. Hu, X. Yu, L. Zhao, Beijing Institute of Technology (China)

683414 Design of objective lenses to extend the depth of field based on wavefront coding [6834-62]

T. Zhao, Z. Ye, W. Zhang, W. Huang, F. Yu, Zhejiang Univ. (China)

683415 Strehl ratio analysis for the wavefront coding system [6834-68]

W. Zhang, Z. Ye, T. Zhao, F. Yu, Zhejiang Univ. (China)

683416 A generalized temporal phase unwrapping algorithm (Invited Paper) [6834-72]

J. Tian, X. Peng, X. Zhao, Shenzhen Univ. (China)

683417 Simultaneous defect inspection on the surface and in the interior of bare wafers using a simple knife-edge test [6834-04]

J. H. Lee, Kongju National Univ. (South Korea); Y. Kim, Mirae Technology (South Korea);

J. Kim, HanTech Co. Ltd. (South Korea); Y. Yoo, Korea Institute of Machinery \& Materials (South Korea)

683418 Research of light reflex surface defects detection technology [6834-118]

J. Tian, Y. Yao, Y. Sun, W. Shi, X. Zhao, X. Yu, Harbin Institute of Technology (China)

\section{SESSION 11 OPTICAL SYSTEM ANALYSIS AND OPTIMIZATION}

683419 Optimization of sampled imaging system with baseband response squeeze model (Invited Paper) [6834-145]

H. Yang, K. Chen, X. Huang, Q. He, G. Jin, Tsinghua Univ. (China)

6834 1A Development in local and global optimization methods [6834-91]

Q. Ding, H. Liu, Luoyang Institute of Electro-Optical Equipment of AVIC (China)

6834 IB Analysis of infrared radiation from optical window with graded temperature distribution [6834-154]

X. Li, Z. Cen, Q. Liu, Zhejiang Univ. (China) 
6834 1C Using Monte-Carlo method for evaluating the imaging through a disturbed medium with random distribution [6834-53]

Q. Liu, X. Li, Z. Cen, S. Deng, Zhejiang Univ. (China)

6834 ID Comparison of ray-tracing methods in self-adaptive grid for inhomogeneous medium [6834-15]

S. T. Deng, X. T. Li, Z. F. Cen, Q. S. Liu, Zhejiang Univ. (China)

SESSION 12 OPTICAL TESTING AND SYSTEM ALIGNMENT

6834 IE Electrically calibrated pyroelectric detector for high-accuracy calibration of UV radiation [6834-94]

X. Shao, Shanghai Institute of Technical Physics (China) and Graduate School of the Chinese Academy of Sciences (China); J. Ding, Y. Yu, J. Fang, Shanghai Institute of Technical Physics (China)

6834 IG Novel method based on DDE technology for computer-aided alignment [6834-129] Y. Huang, L. Li, Beijing Institute of Technology (China)

$68341 \mathrm{H} \quad$ Research on measurement of lens centering errors based on image processing [6834-98] Y. Lin, G. Dong, Y. Huang, Y. Niu, Tianjin Univ. (China)

\section{POSTER SESSION}

$68341 Q \quad$ Optical design of a synthetic aperture ladar antenna system [6834-02]

C. Cao, X. Zeng, X. Zhao, H. Liu, X. Man, Xidian Univ. (China)

$68341 \mathrm{IR}$ Design of a wide field of view infrared scene projector [6834-06]

Z. Jiang, L. Li, Y. Huang, Beijing Institute of Technology (China)

6834 is Improved first Rayleigh Sommerfeld method for investigating microlens array with long focal depth and small f-number [6834-07]

J. Liu, F. Sun, C. Hu, G. Zhang, Y. Liu, Beijing Jiaotong Univ. (China)

$68341 \mathrm{U}$ Algorithm realization of median filter in multiple environments testing conditions for lowlevel-light sight devices measurement system [6834-10]

Y. Gao, S. Tian, NanYang Institute of Technology (China) and NanJing Univ. of Science and Technology (China); B. Chang, Y. Qiu, NanYang Institute of Technology (China); J. Qiao, NanYang Institute of Technology (China) and NanJing Univ. of Science and Technology (China)

$68341 \mathrm{~V}$ Multi-alkali photocathode thermal performance analysis of image intensifier based on lowhigh temperature environment testing conditions [6834-11]

Y. Gao, S. Tian, NanYang Institute of Technology (China) and NanJing Univ. of Science and Technology (China); B. Chang, Y. Qiu, NanYang Institute of Technology (China); J. Qiao, NanYang Institute of Technology (China) and NanJing Univ. of Science and Technology (China) 
6834 IW Influence of temperature on fractal dimension of dynamic scattered light intensity signal of ultrafine particles [6834-13]

J. Shen, B. Tan, Q. Ding, S. Yang, Shandong Univ. of Technology (China)

$68341 Y \quad$ Effect of radius mismatch on performance of segmented telescopic systems [6834-17]

D. Cheng, Y. Wang, M. M. Talha, J. Chang, Beijing Institute of Technology (China); H. Hua, College of Optical Sciences, Univ. of Arizona (USA)

683412 Extrapolation method to extend the dynamic range of the Shack-Hartmann wave-front sensor [6834-20]

H. Li, H. Song, Institute of Optics and Electronics (China) and Graduate School of Chinese Academy of Sciences (China); X. Rao, C. Rao, J. Yang, Institute of Optics and Electronics (China)

683420 Application of a white-light interferometric measuring system as co-phasing the segmented primary mirrors of the high-aperture telescope [6834-22]

H. Song, H. Li, Institute of Optics and Electronics (China) and Graduate School of Chinese Academy of Sciences (China); H. Xian, Institute of Optics and Electronics (China); J. Huang, S. Wang, Institute of Optics and Electronics (China) and Graduate School of Chinese Academy of Sciences (China); W. Jiang, Institute of Optics and Electronics (China)

$683421 \quad$ Method for calculating the center position of collimated laser beam spots [6834-26] G. Wu, L. Wu, Y. Cang, Xi'an Institute of Optics and Precision Mechanics (China) and Graduate School of the Chinese Academy of Sciences (China); L. Chen, Xi'an Institute of Optics and Precision Mechanics (China)

683422 Particle size measurement system of the aerosol time-of-flight mass spectrometer optimization study [6834-27]

W. Zhao, X. Gu, L. Hao, M. Huang, H. Zheng, L. Fang, W. Zhang, Anhui Institute of Optics and Fine Mechanics (China)

683423 Dark point algorithm: a new method to test periodic structures of optical instruments [6834-31]

D. Cai, Y. Song, Univ. of Science and Technology of China (China)

\section{Part Two}

683424 Spherical aberration correction of Gaussian beam [6834-32]

Q. Li, Xidian Univ. (China)

683425 Measurement of self-organization pattern in dielectric barrier discharge by a special photoelectronic detection system [6834-33]

Z. Zhao, L. Dong, Y. Qi, Y. He, Y. Li, Hebei Univ. (China)

683427 Study on the photo-electrical characteristics of different patterns in dielectric barrier discharge by using photoelectricity method [6834-36]

Y. Qi, L. Dong, Z. Zhao, Y. Li, Hebei Univ. (China)

683428 Improvement in design of panoramic annular lens using cemented lenses [6834-37] S. Niu, J. Bai, X. Hou, G. Yang, Zhejiang Univ. (China) 
6834 2A Simulation of the phase-shift and anti-vibration in wavefront time-domain algorithm [6834-40]

L. Tang, Q. Hao, Q. Zhu, Beijing Institute of Technology (China)

6834 2B Athermalization for infrared dual field-of-view optical system [6834-42]

C. Yang, S. Li, Huazhong Institute of Electro-Optics (China)

$68342 \mathrm{D}$ Comparison of signals under top-hat and Gaussian beam excitations in surface thermal lens technique [6834-49]

M. Liu, Institute of Optics and Electronics (China) and Graduate School of Chinese Academy of Sciences (China); B. Li, Institute of Optics and Electronics (China); H. Hao, Institute of Optics and Electronics (China) and Graduate School of Chinese Academy of Sciences (China)

$68342 \mathrm{E} \quad$ Microscope auto-focusing system with the self-adaptive mountain-climbing search method based on PC control [6834-50]

L. Xu, Z. Ye, J. Wu, X. Yan, F. Yu, Zhejiang Univ. (China)

$68342 \mathrm{~F} \quad$ Modulation transfer function measurement of charge-coupled devices using frequencyvariable fringe patterns [6834-54]

L. Zhao, H. Feng, Z. Xu, Zhejiang Univ. (China)

$68342 \mathrm{G}$ Analysis of resolution criterion and aberrations for Fizeau interferometer [6834-55]

S. Wang, Institute of Optics and Electronics (China) and Graduate School of the Chinese Academy of Sciences (China); C. Rao, W. Jiang, Institute of Optics and Electronics (China)

$68342 \mathrm{l}$ Observation of aerosol with a compact lidar over Hefei, China [6834-59]

Z. Liu, J. Liu, W. Liu, X. Zhao, S. Huang, W. Feng, F. Xiao, Anhui Institute of Optics and Fine Mechanics (China)

$68342 \mathrm{~J}$ The effect of beam incident angles on cube corner retro-reflector measurement accuracy [6834-63]

J. Ouyang, Henan Polytechnic Univ. (China); W. Liu, X. Qu, Tianjin Univ. (China); Y. Yan, Henan Polytechnic Univ. (China)

$68342 \mathrm{~K}$ The optimal design of TIR lens for improving LED illumination uniformity and efficiency [6834-67]

Y. Zhen, Z. Jia, Xian Shiyou Univ. (China); W. Zhang, Zhejiang Univ. (China)

$68342 \mathrm{~L}$ Design of double refractive pattern recognition system for optical low pass filter [6834-69] $X$. Li, S. Jin, L. Wang, China Jiliang Univ. (China)

$68342 \mathrm{M}$ A subpixel localization method based on edge diffraction [6834-71]

Y. Wang, M. Peng, X. Cheng, Foshan Univ. (China)

$68342 \mathrm{~N} \quad$ Evaluation of the sphericity measurement uncertainty for the fiber point diffraction interferometer [6834-74]

L. Chen, D. Sha, Beijing Institute of Technology (China) 
683420 A new method of evaluating counting efficiency based on signal amplitude response function [6834-75]

J. Yang, F. Gu, G. Peng, B. Bian, J. Lu, Nanjing Univ. of Science and Technology (China)

$68342 \mathrm{P}$ Research on design of optimum phase mask for wave-front coded imaging system [6834-80]

H. Zhao, H. Feng, Q. Li, Zhejiang Univ. (China)

$68342 \mathrm{R}$ Preliminary analysis and experiment of thermal influence on a large-aperture mirror [6834-82]

W. Hu, Beijing Institute of Technology (China); P. Xu, Beijing Institute of Space Mechanics and Electronics (China); H. Zhang, L. Zhao, G. Bian, X. YU, X. Hu, Beijing Institute of Technology (China)

$68342 \mathrm{~S} \quad$ Research of the grid computing system applied in optical simulation [6834-85] W. Jin, Y. Wang, Q. Liu, Z. Cen, X. Li, Y. Lin, Zhejiang Univ. (China)

$68342 \mathrm{U}$ Application of MATLAB in optical alignment [6834-89]

S. Xiao, Y. Tang, Changchun Univ. of Science and Technology (China)

$68342 \mathrm{~V}$ The wavefront aberration analysis and testing accuracy evaluation for the large aberration aspheric system based on the best fit sphere [6834-93]

J. Weng, Y. Yang, D. Liu, Y. Shen, Y. Zhuo, Zhejiang Univ. (China)

$68342 \mathrm{~W} \quad$ A robust and efficient point matching method for stereovision measurement using dynamic programming [6834-97]

P. Sun, N. Lu, Beijing Information Science and Technology Univ. (China)

$68342 \mathrm{X} \quad$ Highly precise nonlinear error calibrating system based on Fabry-Perot interferometer [6834-99]

J. Ma, Y. Li, C. Yin, Tsinghua Univ. (China)

$68342 Y \quad$ Experimental study on Zeeman-birefringence dual-frequency laser interferometer with mid-frequency difference [6834-100]

Y. Zhang, Y. Li, S. Zhang, Tsinghua Univ. (China)

$68342 Z$ Measurement of target deformation under laser shock with optical beam shading technique [6834-101]

G. Dai, Z.-H. Shen, J. LU, X. W. Ni, Nanjing Univ. of Science and Technology (China)

683430 CCD-based on-line thickness measurement system for calender [6834-103]

L. Guo, Tsinghua Univ. (China); Y. Fan, G. Zhang, Tianjin Univ. (China); K. Chen, Tsinghua Univ. (China)

683431 A digital optical autocollimation method for measuring 2D small angle [6834-105]

L. Ma, B. Yan, N. Lu, Beijing Institute of Machinery (China)

683432 A specially designed optical system for measurement of the characteristic of square super-lattice pattern in DBD [6834-107]

H. Zhao, L. Dong, W. Xie, W. Fan, Hebei Univ. (China) 
683433 An optical method of online measurement for the thickness of thin films [6834-108] M. Song, Dalian Nationality Univ. (China); Y. Zheng, Liaoning Normal Univ. (China) Y. LU, Y. QU, Dalian Nationality Univ. (China)

683434 Research on field correctors of the infrared space optical remote sensor [6834-111] B. Hui, J. Li, Shenzhen Univ. (China); Y. Pei, Shanghai Institute of Technical Physics (China); Q. Wu, Shenzhen Univ. (China)

683435 Key techniques in an absolute measurement method of spherical lens [6834-113] S. Wu, T. Zhou, D. Sha, J. Lin, L. Chen, Beijing Institute of Technology (China)

683437 Research on color encoding structured light 3D measurement technology [6834-116] Y. Fu, G. Liu, Beijing Institute of Machinery (China)

683438 Simulation of atmospheric turbulence layers with phase screens by JAVA [6834-117] X. Zhang, W. Chen, X. YU, J. Yan, Beijing Institute of Technology (China)

6834 3A A novel method of lens initial structure selection: study on structures-aperture relationship of finite image distance achromatic spherical microscope objective with larger numerical aperture [6834-128]

N. Liu, Y. Zhang, F. Fang, Tianjin Univ. (China)

6834 3B Design of an FT-NIR spectrometer for online quality analysis of traditional Chinese medicine manufacturing process [6834-130]

R. Zhu, L. Wu, S. Wang, L. Ye, Z. Ding, Zhejiang Univ. (China)

6834 3C A high-accuracy dual-channel method of measurement on visible light transmittance of telescope system [6834-132]

J. LU, Y. Xiang, L. WU, K. Yin, Changchun Univ. of Science and Technology (China)

6834 3D Study of CAD-based laser guiding measurement technology [6834-137]

Y. Yan, J. Ouyang, Henan Polytechnic Univ. (China); W. Liu, Tianjin Univ. (China); F. Xia, Henan Polytechnic Univ. (China)

$68343 \mathrm{E} \quad$ Specular surface measurement by using a moving diffusive structured light source [6834-139]

H. Guo, T. Tao, Shanghai Univ. (China)

6834 3F Infrared telephoto lens design of hybrid optoelectronic joint transform correlator [6834-1 40] F. Guo, H. Wang, L. Li, N. Yin, W. Wang, Changchun Univ. of Science and Technology (China)

$68343 \mathrm{G}$ Information entropy characteristic of the light scattering signal amplitude distribution of aerosols [6834-141]

F. Gu, J. Yang, B. Bian, A. He, Nanjing Univ. of Science and Technology (China)

$68343 \mathrm{H} \quad$ Optical measurement of discharge pattern in dielectric barrier discharge system [6834-144]

W. Liu, L. Dong, H. Wang, Y. He, Hebei Univ. (China) 
683431 Michelson interferometer in a 2D photonic crystal utilizing self-collimation effect [6834-146] X. Chen, Minjiang Univ. (China); Y. Qiu, Y. Wang, Fujian Normal Univ. (China); N. Lin, G. Lin, Minjiang Univ. (China); H. Hong, B. Ni, Fujian Normal Univ. (China)

6834 3J Optical fiber method for measuring small plane flatness error [6834-147] S. Jin, Y. LV, Q. S. Chen, Beijing Institute of Machinery (China)

6834 3K Area testing study of arbitrary shape plane object based on CCD matrix [6834-148] S. Jiang, D. Liu, W. Wang, Changchun Univ. of Science and Technology (China)

6834 3L Equipment for 2D profile measuring of aspheric microscope condenser in mass production [6834-149]

X. Cheng, J. Ma, Tsinghua Univ. (China); Y. Zhang, Motic China Group Co., Ltd. (China)

$68343 \mathrm{M} \quad$ A novel optical tweezers system [6834-151]

X. Feng, J. Fang, T. Zhu, C. Zhao, J. Fan, Soochow Univ. (China)

$68343 \mathrm{~N}$ Optical design of free-form bicycle lamp [6834-152]

C. Tian, Z. Cen, S. Deng, J. Wang, Zhejiang Univ. (China)

$68343 \mathrm{P}$ Research and design of an optical system of biochemical analyzer based on the narrowband pass filter [6834-160]

Z. Xiao, K. Chen, Guilin Univ. of Electronic Technology (China)

$68343 R$ The influence of high-order dispersion on femesecond solitons [6834-165]

Z. Wang, Z. Li, Y. Liu, J. Chen, Z. Li, Yanshan Univ. (China)

683435 Distributed optical fiber sensor for multi-point temperature measurement [6834-166]

H. Wang, Z. Wang, Z. Bai, Z. Li, Yanshan Univ. (China)

$68343 \mathrm{U}$ Error analysis for integrating sphere of color measuring system [6834-169]

S. Jin, K. Yuan, China Jiliang Univ. (China)

6834 3V Analytical method of genetic algorithm in fiber grating sensing system with transverse uniform stress [6834-170]

Z. Li, W. Yin, H. Wang, Z. Zhou, Yanshan Univ. (China)

$68343 \mathrm{~W}$ Technology of wavelength funing based on refractive optical lever and its application in optical spectrum analysers [6834-171]

Y. Qiu, H. Xu, Y. Gao, Fujian Normal Univ. (China)

$68343 \mathrm{X}$ Scene simulation optics in testing of dual-field angle infrared imagers [6834-173]

Y. Zheng, J. Gao, J. Wang, H. Chen, Xi'an Institute of Applied Optics (China)

$68343 Y$ Design of infrared zoom system with rotating lens group [6834-174]

Y. Li, C. Yang, S. Li, Huazhong Institute of Electro-Optics (China)

683440 Research on a system and method of automated whole-field measurement of optical glass stress [6834-181]

L. Zhang, Y. Tang, T. Bai, Beijing Institute of Technology (China) 
683442 A prototype system for high precision 3D measurement based on grating method [6834-184]

Z. Li, Y. Shi, C. Wang, G. Zhou, D. Qin, Huazhong Univ. of Science and Technology (China)

683443 A novel ellipsometer for measuring thickness of oxide layer on the surface of silicon sphere [6834-106]

J. Zhang, Y. Li, Tsinghua Univ. (China)

683446 Simulation of multi-reentrant two-mirror ring cavity lasers [6834-190]

F.-H. Tseng, S.-K. Liu, National Kaohsiung Univ. of Applied Sciences (Taiwan, China)

Author Index 
Downloaded From: https://www.spiedigitallibrary.org/conference-proceedings-of-spie on 26 Apr 2023

Terms of Use: https://www.spiedigitallibrary.org/terms-of-use 


\title{
Conference Committee
}

\author{
Conference Chairs \\ Yongtian Wang, Beijing Institute of Technology (China) \\ Theo T. Tschudi, Technische Universität Darmstadt (Germany) \\ Jannick P. Rolland, College of Optics and Photonics, University of \\ Central Florida (USA) and University of Central Florida (USA) \\ Kimio Tatsuno, Hitachi, Ltd. (Japan)
}

Program Committee

Genrui Cao, Beijing Institute of Technology (China)

Lei Chen, Nanjing University of Science \& Technology (China)

Toshihide Dohi, OptiWorks, Inc. (Japan)

Yves A. Gilliand, FISBA OPTIK AG (Switzerland)

Hong Hua, College of Optical Sciences, The University of Arizona (USA)

Seung-Woo Kim, Korea Advanced Institute of Science and

Technology (South Korea)

Jong-Ung Lee, Cheongju University (South Korea)

Tiegen Liu, Tianjin University (China)

Juan L. Rayces, J.L. Rayces Consulting, Inc. (USA)

Masato Shibuya, Tokyo Polytechnic University (Japan)

Prudence M. J. H. Wormell, Imperial College London (United Kingdom)

Lijiang Zeng, Tsinghua University (China)

Weiqian Zhao, Beijing Institute of Technology (China)

Session Chairs

1 Nano-and Micro-Optics

Theo T. Tschudi, Technische Universität Darmstadt (Germany)

2 Illumination System Design

Hisao Kikuta, Osaka Prefecture University (Japan)

3 Astronomical and Space Optics

Jannick P. Rolland, College of Optics and Photonics, University of Central Florida (USA) and University of Central Florida (USA)

$4 \quad$ Head-Mounted Display Design

Yongtian Wang, Beijing Institute of Technology (China)

5 Compact Optics

Kevin P. Thompson, Optical Research Associates (USA) 
Interferometry in Optical Testing

Qun Hao, Beijing Institute of Technology (China)

$7 \quad$ Testing for Aspheric Surfaces

Yves A. Gilliand, FISBA OPTIK AG (Switzerland)

8

Novel System Design

Dayong Wang, Beijing University of Technology (China)

9

Wavefront Sensing and Coding

Yongying Yang, Zhejiang University (China)

10

Optical Measurement

Huaidong Yang, Tsinghua University (China)

11 Optical System Analysis and Optimization

Yifan Huang, Beijing Institute of Technology (China)

12

Optical Testing and System Alignment

Jindong Tian, Shenzhen University (China) 


\title{
Symposium Committees
}

\author{
General Chairs \\ Brian Culshaw, University of Strathclyde (United Kingdom) \\ Bingkun Zhou, Tsinghua University (China) and COS-Chinese Optical \\ Society (China) \\ General Cochairs
}

Arthur Chiou, National Yang-Ming University (Taiwan, China)

Mitsuo Takeda, University of Electro-Communications (Japan)

Chungli Bai, Chinese Academy of Sciences (China)

Seung-Han Park, Yonsei University (South Korea)

Zhizhan Xu, Shanghai Institute of Optics and Fine Mechanics

(China)

Jianlin Cao, China Ministry of Science and Technology (China)

Junhao Chu, Shanghai Institute of Technical Physics (China)

Jingming Kuang, Beijing Institute of Technology (China)

Xiaomin Ren, Beijing University of Posts and Telecommunications (China)

Dingbo Kuang, Shanghai Institute of Technical Physics (China)

Guozheng Yang, Institute of Physics (China)

Honorary Chairs

Daheng Wang, Chinese Academy of Sciences (China)

Guoguang Mu, Nankai University (China)

Technical Program Chair

Songlin Zhuang, Shanghai University of Science and Technology (China)

Technical Program Cochairs

Xun Hou, Xian Institute of Optics and Precision Mechanics (China)

Qian Mao, Wuhan Research Institute of Posts and Telecommunications (China)

Xu Liu, Zhejiang University (China)

Local Organizing Committee Chair

Shusen Xie, Fujian Normal University (China)

Local Organizing Committee Cochairs

Guoqiang Ni, Beijing Institute of Technology (China)

Qihuang Gong, Peking University (China)

Ying Gu, PLA General Hospital (China)

Huilin Jiang, Changchun University of Science and Technology (China) 
General Secretary

Guoqiang Ni, Beijing Institute of Technology (China)

Administrative Vice General Secretary

Boyu Ding, Beijing Institute of Technology (China)

Vice General Secretaries

Hanyi Zhang, Tsinghua University (China)

Ya Cheng, Shanghai Institute of Optics and Fine Mechanics (China)

Zhongwei Fan, Academy of Opto-electronics (China)

Jianxin Chen, Fujian Normal University (China)

Lan Wu, Zhejiang University (China)

Shaowen Wang, COS-Chinese Optical Society (China)

Yuejin Zhao, Beijing Institute of Technology (China)

Chongxiu Yu, Beijing University of Posts and Telecommunication (China)

Jun Ruan, China Solid State Lighting Research and Industry Alliance

(China)

Local Organizing Committee Members

Kangnan Qi, Beijing Optical Society (China)

Chunqing Gao, Beijing Institute of Technology (China)

Tiegen Liu, Tianjin University (China)

Lanxing Shao, Shanghai Optical Society (China)

Zaixuan Zhang, Chinese Jiliang University (China)

Hongda Chen, Institute of Semiconductors (China)

Baosheng Liu, Beijing Optical Society (China)

Xin Wang, Hubei Optical Society (China)

Lin Zhai, COS-Chinese Optical Society (China)

Zhiqiang Zhu, East China Normal University (China)

Lei Xu, Fudan University (China)

Hezhou Wang, Zhongshan University (China)

Zhiming Yi, Ofstar Tech Company, Ltd., Shenzhen (China) 


\section{Introduction}

Photonics Asia met in Beijing, China during the week of 11-15 of November 2007.

By all indications it was a rousing success. Photonics Asia opened the conference with a memorable opening ceremony with SPIE leaders introduced from throughout the world, followed by four Plenary speeches:

- Solid State Lighting

by Jinmin Li of the Institute of Semiconductors of the Chinese Academy of Science

- The National Ignition Facility also known as the World's Largest Optical System

by Christopher Stolz of Lawrence Livermore National Laboratory in the USA

- A Brief Introduction to Biophotonics and Selected Applications by Arthur Chiou of the National Yang-Ming University in Japan

- Terahertz Wave Photonics in Gas and its Spectroscopic Applications by X.-C. Zhang of the Rensselaer Polytechnic Institute in the USA

Photonics Asia started as a new conference in 2002 in Shanghai, followed by a second conference held also in Beijing in 2004. This 3rd Photonics Asia (2007) was managed and sponsored by SPIE and the Chinese Optical Society (COS). Many corporation leaders participated in the conference.

Attendance at the conference has been growing reaching a total over the entire conference of 1269 papers, 615 posters, and 127 invited talks, including a strong international presence this year. The conference topics within the Optical Design and Testing conference span a wide variety of fields including

- Astronomical and space optics

- Wavefront sensing and coding

- Novel system design

- Illumination system design

- Compact optics

- Head-mounted display design

- Nano- and Micro-optics

- Optical system analysis and optimization

- Optical Measurement

- Optical testing and system alignment

- Testing for aspheric surfaces

- Interferometry in optical testing 
It was a pleasure working with SPIE and Photonics Asia 2007, and we look forward to seeing you in 2009 !

Yongtian Wang

Theo T. Tschudi

Jannick P. Rolland

Kimio Tatsuno 